\title{
UM RESGATE A OBRA DE GEORGES BERTRAND: CONTRIBUIÇÕES TEÓRICAS E METODOLÓGICAS NA ANÁLISE DA PAISAGEM
}

\author{
A RESCUE THE GEORGES BERTRAND'S WORK: THEORETICAL AND \\ METHODOLOGICAL CONTRIBUTIONS IN LANDSCAPE ANALYSIS
UN RESCATE DE LA OBRA DE GEORGES BERTRAND: CONTRIBUCIONES TEÓRICAS Y METODOLÓGICAS EN EL ANÁLISIS DEL PAISAJE

\author{
Gabriella Cristina Lima ${ }^{1}$ https://orcid.org/ 0000-0002-4228-1934 \\ Anderson Geová Maia de Brito² https://orcid.org/0000-0003-1351-5110 \\ Juliana Felipe Farias ${ }^{3}$ https://orcid.org/ 0000-0002-0185-2411
}

\footnotetext{
${ }^{1}$ Mestranda em Geografia - Universidade Federal do Rio Grande do Norte. E-mail: limagabriella8@gmail.com

${ }^{2}$ Mestrando em Geografia - Universidade Federal do Rio Grande do Norte. E-mail: andersongeova17@gmail.com

${ }^{3}$ Doutora em Geografia. Professora da Universidade Federal do Rio Grande do Norte. E-mail: julianafelipefarias@yahoo.com.br
}

\section{RESUMO}

Com o intuito de corroborar com o pensamento Geográfico acerca da paisagem, o presente estudo apresenta um artigo de revisão bibliográfica que aborda uma análise sobre as contribuições teóricas e metodológicas de Georges Bertrand para o referido tema. Presente em um importante contexto para a ciência geográfica, Bertrand desenvolve uma análise integrada da paisagem, na qual culmina em uma gama de aplicações, expandindo-se pelas pesquisas brasileiras. Diante do contexto, buscou-se realizar uma abordagem que contemplasse os acontecimentos e bases histórico-filosóficas que incentivaram o autor em sua concepção integradora, como sua metodologia influenciou na análise da paisagem, desenvolvendo conceitos e por fim, a aplicação de seus legados para a ciência geográfica através da cartografia.

Palavras-chave: Geografia, Bertrand, Paisagem.

\begin{abstract}
In order to corroborate with the geographic study on the landscape, the present study introduces an article of bibliographical revision that approaches an analysis about the theoretical and methodological aspects of Georges Bertrand for the mentioned subject. Present in an important context for a geographic science, Bertrand presents an integrated analysis of landscape, culminating in many applications, expanding by Brazilian research. Against the background, an attempt was made to contemplate historical-philosophical events and bases that would encourage the author in his
\end{abstract}


integrative conception; As this methodology influenced the analysis of the landscape, developing concepts and methods, an application of its legacies to a geographic economy through cartography

Keywords: Geography, Bertrand, Landscape.

\section{RESUMEN}

Con el fin de corroborar con el pensamiento geográfico acerca del paisaje, el presente estudio presenta un artículo de revisión bibliográfica que aborda un análisis sobre las contribuciones teóricas y metodológicas de Georges Bertrand para el referido tema. En un importante contexto para la ciencia geográfica, Bertrand desarrolla un análisis integrado del paisaje, en la que culmina en una gama de aplicaciones, expandiéndose por las encuestas brasileñas. Ante el contexto, se buscó realizar un abordaje que contemplara los acontecimientos y bases histórico-filosóficas que incentivaron al autor en su concepción integradora; como su metodología influenció en el análisis del paisaje, desarrollando conceptos y por fin, la aplicación de sus legados a la ciencia geográfica a través de la cartografía.

Palabras clave: Geografía, Bertrand, Paisaje.

\section{INTRODUÇÃO}

Até meados da década de 1960 a análise da paisagem e as relações dialéticas existentes por trás dela, foram caindo em desuso nas academias e escolas científicas, entretanto, com a ascensão das problemáticas ambientais e da transformação social e cultural no mundo contemporâneo, não só novas paisagens surgiram como a paisagem passou a ter um viés tanto ecológico econômico como cultural.

No âmbito da Geografia, uma nova maneira de analisar a paisagem foi apresentada pelas escolas russa e francesa, principalmente pelo geógrafo francês Georges Bertrand, que influenciado pela Geografia Teórico-Quantitativa e pela Teoria Geral dos Sistemas de Bertalanffy (1973) inseriu um enfoque singular aos estudos geográficos daquela época, através da análise integrada da paisagem, a qual ainda era estudada pelo viés da Geografia Tradicional, ou seja, de maneira fragmentada.

Segundo Bertrand (1972) o conceito de paisagem àquela época estava se tornando obsoleto e até mesmo impreciso frente a crescente diversidade de interpretações e abordagens que atribuíam a paisagem um qualificativo de restrição. E como forma de suprir essa demanda teórico-metodológica na análise da Paisagem, Bertrand em seu artigo "Paysage et géographie physique globale: Esquisse méthodologique" propôs através da categorização da paisagem uma abordagem híbrida (qualidade de tudo o que resulta de elementos de natureza distinta), susceptível de associação dos contrários: natureza e sociedade, subjetivo e objetivo, individual e coletivo, teórico e prático, ciência e cultura, ordinário e extraordinário. 
Abordagem híbrida esta, que mais tarde reformulada, passou a consistir no sistema GTP (Geossistema, Território e Paisagem), no qual o Geossistema é a fonte de sustentação através de suas características bio-físico-químico; o Território como recurso por seu aspecto socioeconômico; e a Paisagem é a identidade, o cultural, o simbólico. Destacando que todos os componentes do sistema possuem dinâmicas próprias, mas que também possuem conexões mútuas entre si.

Todavia, o conceito de Paisagem não pode estar apenas embasado em questões estéticas, ou aquilo que podemos alcançar com nossa percepção, este conceito, perpassa muitas vezes o que julgamos conhecer, apresentando singularidades e traços marcantes em seus estudos, o que torna uma fácil identificação. Para tanto, os trabalhos de cunho teórico e revisionais têm uma importância relevante na construção e desenvolvimento da ciência, pois assumem um papel de síntese do conhecimento, de catalogação e de reunião de escritos de uma determinada abordagem para a transferência de conhecimento entre o cientista e os pares (FIGUEIREDO, 1990).

Dessa forma, o objetivo central deste artigo é a discussão permeada nas contribuições de Georges Bertrand acerca da aplicação do conceito de Paisagem com caráter teórico e introdutória em um enfoque dentro da ciência geográfica, discutindo, de que maneira a construção e evolução deste conceito contribuiu para análises de forma integrada e que fomentem relevância aos temas estudados.

\section{GEORGES BERTRAND E O PENSAMENTO INTEGRADO}

Ao tecer uma análise acerca das influências que culminaram nas formulações téoricometodológicas de Bertrand, é possível constatar que tal conjunto foi sendo construído a partir de uma perspectiva cumulativa, acompanhando o desenvolvimento da ciência geográfica. Diante desse contexto, faz-se necessária a análise dos acontecimentos que contribuíram para a compreensão como um todo dessas influências.

Em meados do século XIX, nos trabalhos realizados por Humboldt (1769-1859) onde era considerado naturalista pelo enfoque do estudo da paisagem baseado nas morfologias do terreno, e Dokuchaev (1846-1903), desenvolvendo o conceito de "paisagem natural", no qual, serviria de base para futuras ideias integradoras para os estudos da categoria paisagem, inferese que a ideia de uma única unidade, a denominada natural, fundamentava a busca pela compreensão entre os fenômenos. Para Cavalcante e Corrêa (2014) tais cientistas alicerçam seus pensamentos nas diversas experiências que tiveram ao longo do globo terrestre, por efeito das suas inúmeras excursões naturalistas. 
Partindo da contribuição a partir da visão naturalista desenvolvida por Humboldt e Dokuchaev, fica evidente que havia a necessidade de estimular uma visão integrada da natureza, a qual, poderia ser subsidiada pelo estudo das relações entre os componentes naturais (solo, clima, vegetação, relevo, fauna), o que Gregory (1992) denomina como síntese naturalista.

Emergindo ao século XX, uma gama de debates acerca das múltiplas técnicas e métodos de se analisar as paisagens. Dentre as formas de avaliação que podem ser destacadas na época, está a linha de pensamento soviética (anos 60/70), pautada em uma preocupação territorial, parte da necessidade de uma reorganização do espaço para considerar aspectos ecológicos relacionados a vegetação e ocupação do solo. Entretanto, é ainda durante o século XX que muitas transformações são observadas, como abordam Bernardino, Oliveira e Diniz (2018, p. 67):

[...] A consolidação do sistema capitalista como um importante vetor de dinamicidade e instabilidade social e política. Com esse sistema econômico, o mundo havia se diferenciado rapidamente desde o reducionismo cartesiano e o positivismo clássico: a realidade era, agora, a das empresas multinacionais, do rápido desenvolvimento industrial, da mecanização da agricultura, do êxodo rural, da urbanização e dos problemas de ordem ambiental (etc.).

Mediante todos os acontecimentos a nível global durante o período, é indubitável que a repercussão e desenrolar das circunstâncias que permeavam as ciências e escolas filosóficas sofreram uma ruptura do seu modo de pensar e agir e de fato, a influência maior da geografia como um todo provinha do ideal regional, a qual "fez com que a pesquisa em geografia física se direcionasse para áreas específicas" GREGORY (1992).

Passando por um período de estagnação, a Geografia Física encontrava-se apenas como um suporte para a espacialização dos fenômenos sociais, desta maneira, introduzem a ação do homem em seus estudos, fazendo com que agora, a atividade antrópica seja introduzida no contexto natural. Sendo considerada um campo vasto e complexo, que analisa as condições e processos naturais de um dado espaço, a Geografia Física esteve até o início da década de 50, sem um método de análise espaço-temporal que permitisse uma análise integradora ente os sistemas ambientais e humanos.

Ainda no século XX, é possível constatar a transição entre o indutivo onde a prioridade estava centrada a partir de fatos não ordenados para uma generalização, para o dedutivo, o qual apresenta um modelo onde inicialmente é percebido em um estágio inicial para permitir a manipulação dos dados e para que sejam tiradas conclusões acerca de algum conjunto de fenômenos, como aborda Gregory (1992). É então que no decorrer do ano de 
1970, podemos destacar o advento da quantificação, onde sua principal condição estava centrada em afirmar que as teorias devem ser sustentadas por fatos, ainda em Gregory (1992, p.78). É possível observar que uma teoria seria qualificada de científica se sua probabilidade matemática fosse alta, mas, se ela fosse baixa ou mesmo zero, então a teoria não seria considerada científica.

Foi então que por meio da adoção do indutivismo, da estatística e da lógica, aprimorou-se uma linguagem comum para as ciências, abordando também uma abordagem sistêmica. É desta forma que podemos observar um sistema complexo, como aborda Christofoletti (1999), constituindo-se de um conjunto organizado de elementos, entre os quais há interações, troca de energia, matéria e informações.

\section{A TEORIA GERAL DOS SISTEMAS: UMA METODIZAÇÃO DOS ESTUDOS DA PAISAGEM}

A abordagem sistêmica iniciada por volta de 1930, tendo como percussor o biólogo Ludwig Von Bertalanffy aparece como um complemento ao pensamento cartesiano, uma vez que, a mesma aparece sem a finalidade de remover tudo aquilo que outrora já havia se constituído enquanto métodos investigativos, mas, é incorporada às ciências para que haja uma maior compreensão da realidade, como aborda Limberger (2006).

É em 1950 que Bertalanffy lança a "General System Theory” (Teoria Geral dos Sistemas), ganhando visibilidade e aplicação em diversas áreas da ciência. Para Vicente e Perez Filho (2013) Bertalanffy propunha, com este novo conceito, uma epistéme complexa; buscava uma linguagem científica única, capaz de englobar todos os campos do

conhecimento. É a partir de então que se viabiliza a análise da particularidade dos fenômenos, abandonando a concepção generalista.

Quando consideramos a ciência geográfica, a abordagem desenvolvida por Bertalanffy viabilizou progresso da intitulada "Nova Geografia". Com a introdução desta teoria na Geografia, foi permitida um melhor delineamento das pesquisas, promovendo também uma maior exatidão no que se refere aos objetos de estudo desta ciência. Alguns autores, como por exemplo Strahler em 1950, aplicando em sistemas de drenagem e constatou que se tratava de um sistema aberto, ademais, outros estudiosos como Chorley (1962), Culling (1957) e Hack (1962) aplicaram a metodologia em suas pesquisas, e corroboraram para o crescimento da Geografia Física.

Todavia, não foi apenas na Geografia Física onde registram-se aplicações da Teoria do biólogo austríaco. Christofoletti $(1979$, p.12) afirma que a Geografia Humana e 
Econômica também fez uso dos conceitos da Teoria Geral dos Sistemas, porém de forma difusa. Destacam-se os trabalhos de Berry em 1964, que se refere a "cidades como sistemas dentro de sistemas de cidades".

O movimento de renovação da Geografia enquanto ciência permeou de forma incisiva um choque em suas bases epistemológicas, como afirmam Jiménez e Canteiro (2002). Este movimento não ocorreu de forma igualitária. Moraes (1994) agrupa a ciência geográfica em três grandes grupos: a Geografia Pragmática (no Brasil, "Teorética"; Geografia Quantitativa ou Nova Geografia), a Geografia Crítica (ou Radical) e a Geografia da Percepção/Comportamento. Diante disso, temos a liderança da Geografia Pragmática por três nomes representativos: Viktor Sotchava, Jean Tricart e Georges Bertrand.

A aplicação desta teoria em uma produção geográfica acontece em 1960, onde por meio dos estudos dos Geossistemas desenvolvido por Sotchava, fazendo-se possível constatar sua execução no que cerne as pesquisas sobre a superfície da Terra. Sotchava (1977, p. 9) diz que os geossistemas são "formações naturais, experimentando, sob certa forma, o impacto dos ambientes social, econômico e tecnogênico". Dessa maneira, o geossistema pode ser definido como formações naturais que se desenvolvem influenciados tanto por fenômenos naturais quanto econômicos e sociais, que alteram sua estrutura e peculiaridades espaciais.

Em Tricart (1977) define um sistema como um conjunto de fenômenos que se processam mediante fluxos de matéria e energia. Esses fluxos originam relações de dependência mútua entre os fenômenos. Surge daí uma entidade global nova, mas dinâmica. Para o autor, é a partir deste conceito que há um dialogo entre as necessidades de análise e de visão integradora, adotando um caráter lógico, em sua concepção é possível aferir que os problemas do meio ambiente são melhor interpretados por meio da análise dos sistemas, uma vez que detém de características próprias, sendo os chamados inputs (entrada), output (saída), retroalimentação (reintrodução de uma saída sob a forma de informação) e clímax (equilíbrio do sistema) não é preciso separar as partes para compreendê-las.

No sistema proposto por Bertrand, abordado por Monteiro (2000, p. 31), o autor propõe que o Geossistema é composto por ação antrópica, exploração biológica e potencial ecológico.” E desta forma, é possível identificar a importância desta teoria para análise da paisagem, uma vez que de maneira sistêmica, a concepção de Geossistemas abordada por Bertrand compreende elementos (fenômenos) que de forma integrada constituem o todo, formando assim um "modelo teórico da paisagem", como denominam Vicente e Perez Filho (2003). 


\section{PROPOSIÇÃO METODOLÓGICA DE BERTRAND NA ANÁlLSE DA PAISAGEM: CLASSIFICAÇÃO DE UNIDADES DA PAISAGEM}

Ao tecer suas primeiras considerações sobre paisagem, Georges Bertrand (1972, p. 141) destaca que “"'Paisagem” é um termo pouco usado e impreciso, e por isto mesmo, cômodo, que cada um utiliza a seu bel prazer, na maior parte das vezes anexando um qualificativo de restrição que altera seu sentido ("paisagem vegetal", etc.)", ou seja,

O problema é de ordem epistemológica. Realmente, o conceito de "paisagem" ficou quase estranho à geografia física moderna e não tem suscitado nenhum estudo adequado. É verdade que uma tal tentativa implica numa reflexão metodológica e pesquisas específicas que escapam parcialmente à geografia física tradicional (BERTRAND, 1972, p. 141).

Problema este que reside no fato de que o estudo da paisagem na Geografia Tradicional era baseado no separativismo de seus componentes. De acordo com Bertrand (1972, p. 141):

A paisagem não é a simples adição de elementos geográficos disparatados. É, em uma determinada porção do espaço, o resultado da combinação dinâmica, portanto instável, de elementos físicos, biológicos e antrópicos que, reagindo dialeticamente uns sobre os outros, fazem da paisagem um conjunto único e indissociável, em perpétua evolução.

Ainda de acordo com Bertrand (1972), embora seja impossível achar um sistema espacial que respeite os limites próprios para cada ordem de fenômenos, a classificação das paisagens permitiria situá-las na dupla perspectiva do tempo e do espaço sem considerar a escala. Com base nisso, o autor propôs uma taxonomia das paisagens dividida em seis níveis têmporo-espaciais como apresentadas na figura 1, baseadas na escala geomorfológica de Cailleux e Tricart. 
Figura 1: Unidades de Paisagem conforme A. Cailleux, G. Viers e J. Tricart (1); M. Sorre (2) e R. Brunet (3).

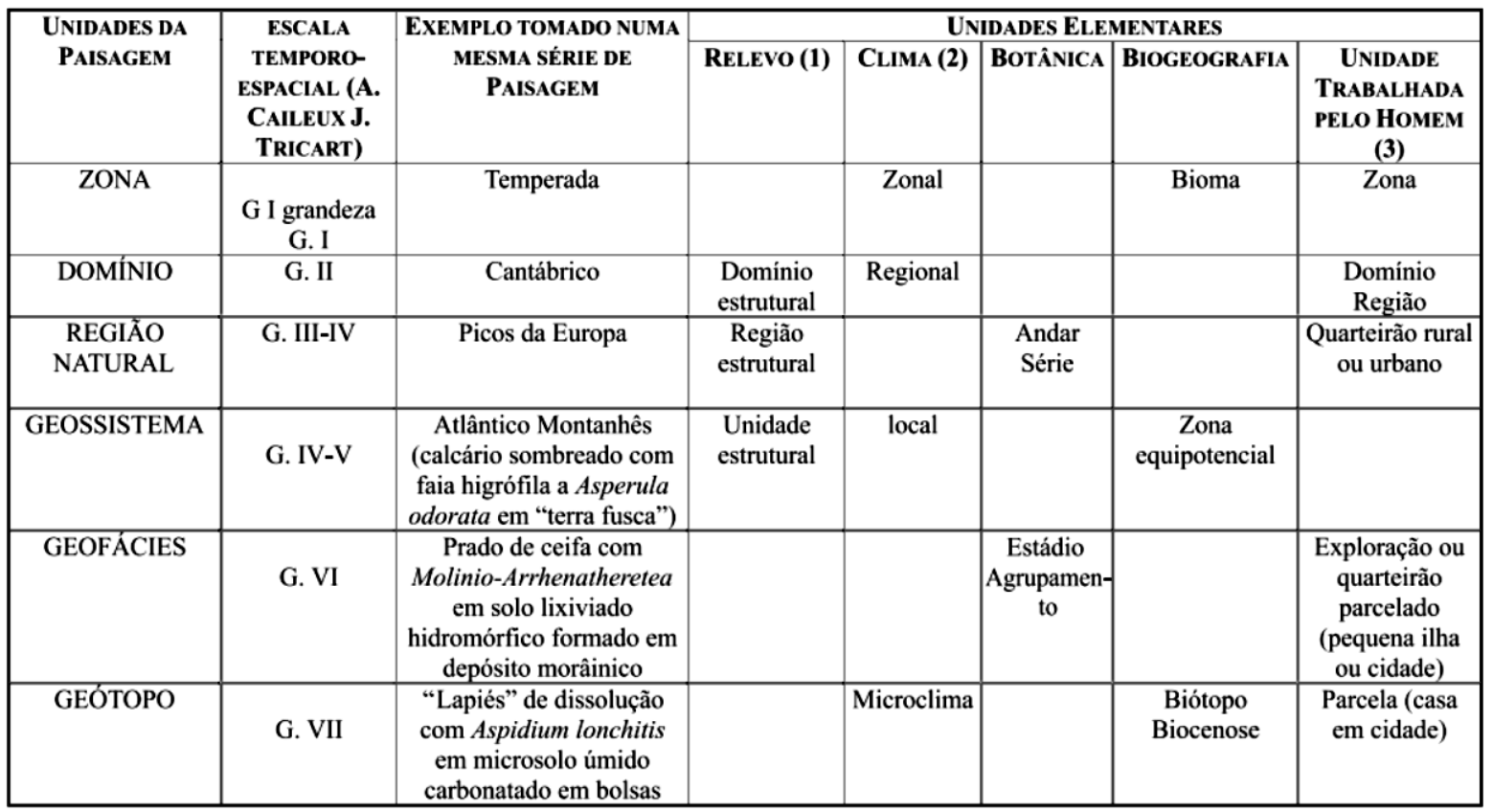

Fonte: Bertrand (1968).

Conforme abordado, a taxonomia proposta por Georges Bertrand (1972) se resume em seis níveis de estruturação da paisagem que se agrupam em unidades superiores (G.I, G.II e G.III-IV) e unidades inferiores (G.IV-V, G.VI e G.VII). Assim sendo - em escala decrescente de grandeza (G.I para o G.VII) —, Zona, Domínio e Região Natural são as unidades superiores e Geossistema, Geofácies e Geótopo, as unidades inferiores (BERTRAND, 1968).

$\mathrm{Na}$ proposição em questão, o geossistema seria uma unidade dimensional compreendida entre alguns quilômetros quadrados e algumas centenas de quilômetros quadrados situado entre a $4^{\mathrm{a}}$ e a $5^{\mathrm{a}}$ grandeza temporo-espacial (BERTRAND, 1972). No qual "a estrutura, as interrelações e a dinâmica que ocorrem em determinada área formando um Geossistema, dão a feição, a fisionomia daquele espaço, que é a própria paisagem visto como sistema, como unidade real e integrada" (TROPPMAIR E GALINA 2006, p. 82).

\section{GEOSSISTEMA: UM ENFOQUE HOLÍSTICO}

A Teoria Geossistêmica, tal como se compreende hoje, foi proposta inicialmente no início da década de 1960 na extinta União Soviética, por Viktor Borisovich Sochava, que não só deu uma nova roupagem à geografia física, como também proporcionou o desenvolvimento 
de novas metodologias de análise. Esse soviético propôs que tal teoria seria "uma forma de estudo de paisagens geográficas complexas, definida como uma unidade dinâmica com organização geográfica própria e um espaço que permite repartição de todos os componentes de um geossistema" (NASCIMENTO \& SAMPAIO, 2004/2005 p.169).

Tendo por base a proposta Geossistêmica de Sochava (1977), Georges Bertrand, busca um aprimoramento da teoria a partir de sua proposição na tipologia espaço-temporal de análise das unidades da paisagem, pois segundo o autor, o geossistema:

[...] se caracteriza por uma morfologia, isto é, pelas estruturas verticais (os geohorizontes) e horizontais (geofácies); um funcionamento, que engloba o conjunto de transformações dependentes da energia solar ou gravitacional, dos ciclos da água, dos biogeociclos, assim como dos movimentos das massas de ar e dos processos de morfogênese; um comportamento específico, isto é, para as mudanças de estado que intervêm no geossistema em uma dada sequência temporal (BERTRAND, 1978, p.51 apud MAGALHÃES; SILVA; ZANELLA, 2010, p. 10).

Outro aspecto do Geossistema em Bertrand que avança além das proposições teóricometodológicas de Sochava é a sua compatibilidade com a escala socioeconômica humana, ou seja, através da intersecção entre o potencial ecológico, a ação antrópica e a exploração biológica, seria possível a realização de estudos geográficos de geomorfogênese e degradação antrópica, conforme pode ser observado na figura 2

Figura 2: Geossistema

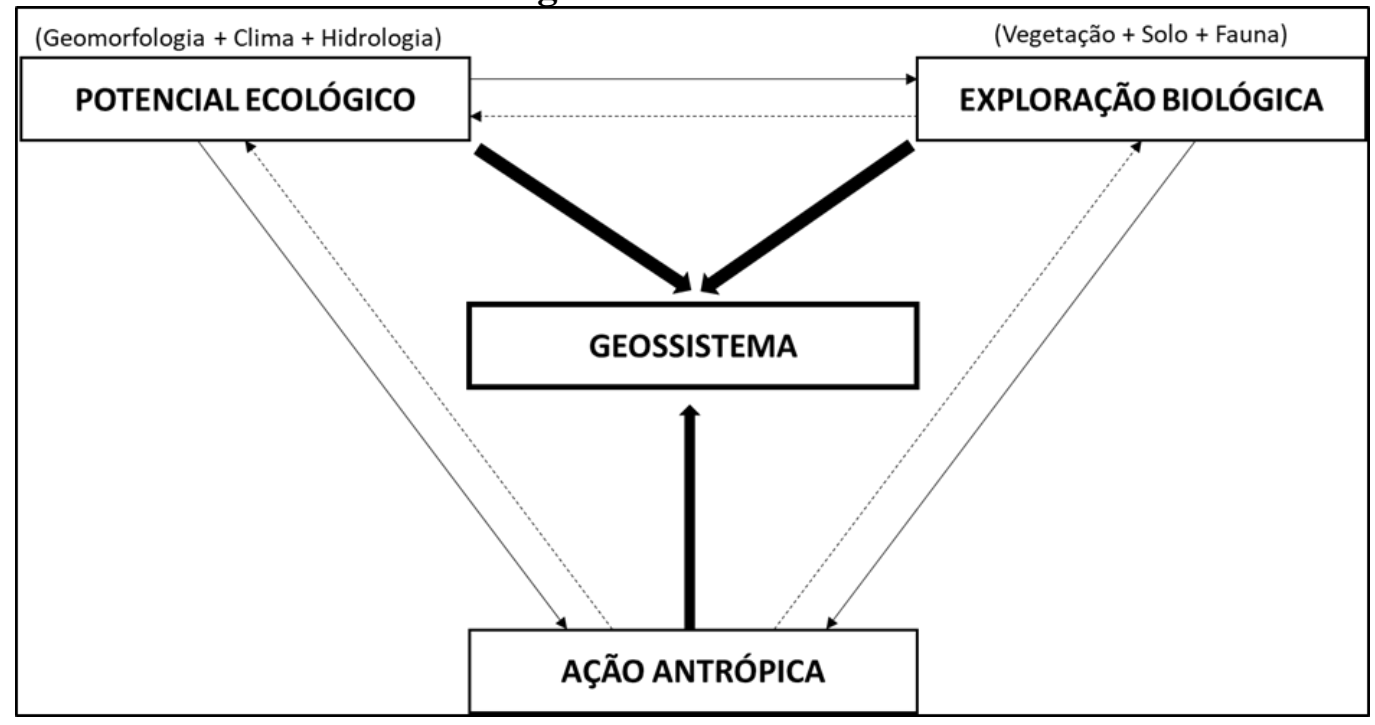

Fonte: Bertrand (1968)

De acordo com Magalhães, Silva e Zanella (2010, p. 11), embora as bases teóricas de Sotchava e de Bertrand confluem para considerar o "geossistema como um conceito territorial, espacialmente delimitado e analisado sob determinada escala", as classificações são deiferenciadas em cada autor. Sotchava (1977) considera que o geossistema ocorre nos 
níveis planetário, regional e topológico, Bertrand (1968) por sua vez, aponta escalas de análises da paisagem mais precisas e as considera a partir da homogeneização dos componentes e características do sistema, as quais ele divide em unidades superiores (zona, domínio e a região natural) e unidades inferiores (geossistema, geofácies e geótopo).

Seguindo a teoria dos sistemas proposta por Sochava e mais tarde aprimorada por Bertrand, Mendonça (1998) destaca que a análise geossistêmica ocorre através do "complexo físico-geográfico" que é se não a conexão da natureza com a sociedade humana, onde são englobados os parâmetros econômicos e sociais humanos em conjunto com a hidrografia, a geomorfologia, a vegetação e a climatologia, que são constituintes do quadro natural de um geossistema. Dessa forma, Mendonça (1998) destaca que o geossistema pode ser estudado por si só e não pela forma limitada de um simples lugar, sendo definido então como:

“[...] uma expressão dos fenômenos naturais, ou seja, o potencial ecológico de determinado espaço no qual há uma exploração biológica, podendo influir fatores sociais e econômicos na estrutura e expressão espacial, porém sem haver necessariamente, face aos processos dinâmicos, uma homogeneidade interna" (MENDONÇA, 1998, p. 49).

Com o conceito de geossistema evidencia-se a possibilidade da geografia enxergar a sociedade através de uma maior interdisciplinaridade com a natureza, se esforçando para transcender as monografias setoriais (BERTRAND; DOLFUSS,1973). A prerrogativa apresenta-se fundamental à geografia em relação aos demais subcampos das ciências sociais, dado seu poder em analisar a relação sociedade natureza na sua interface (BERTRAND, 1978a).

Em caráter de síntese, o geossistema constitui-se então enquanto um sistema natural, complexo e integrado, dotado de um dinamismo temporo-espacial, que considera as ações antrópicas como agentes modificadores, não tanto ao ponto de transformar ou descaracterizar o geossistema. Neste sentido, para a realização da análise geossistêmica deve-se ter como base:

[...] a interação dos três componentes do geossistema (componentes abióticos - litosfera, atmosfera e hidrosfera; componentes bióticos - fitomassa e zoomassa; e componentes antrópico-sociais) são formadas paisagens singulares em constante transformação, com dinamismo interno e externo, mostrando sua capacidade de sucessão temporal com estrutura e funcionamento próprios (MAGALHÃES; SILVA; ZANELLA, 2010, p. 12).

No entanto, em razão da sua definição depender da natureza das pesquisas realizada

s, uma vez que se ela é uma realidade de essência histórica (social), as perspectivas naturalistas não são suficientes para esgotar o seu significado e dinâmica. A esse respeito, Bertrand (1984) enfatiza que a paisagem está enraizada no coração da natureza e do social, no 
núcleo das relações sociais sendo, antes de tudo, um estudo necessário, mas também paradoxal.

Autores como Ab'Saber (2003); Christofoletti, Monteiro (1982, 1987); Troppmair (1983, 2000) e Passos (2006) contribuíram ao desenvolvimento da temática no Brasil. No entanto, nortearam e corroboraram de modo geral, suas discussões praticamente nas mesmas concepções teóricas dos demais autores brasileiros, com diferenciação de Passos, que reconheceu grande parte da obra de Bertrand (NEVES, 2017). Esta diferenciação entre autores propiciou estudos que são fundamentais para identificar as singularidades da Paisagem dentro da Geografia e seus temas afins.

A utilização da proposição teórico-metodológica do geossistema tem possibilitado a pesquisadores, a realização de estudos ambientais de maneira integrada, fornecendo uma percepção mais ampla do meio natural, uma vez que a delimitação dos sistemas ambientais em associação com a ecodinâmica de Tricart (1977) possibilita identificar o grau de vulnerabilidade do ambiente em função dos processos degradacionais deste (MAGALHÃES; SILVA; ZANELLA, 2010).

\section{O SISTEMA GTP (GEOSSISTEMA-TERRITÓRIO-PAISAGEM)}

Após sua erradicação no campo científico, a proposição teórico-metodológica da Análise Integrada da Paisagem e os Geossistemas de Bertrand (1968) sofreu severas críticas, tanto por sua limitação a uma análise superficial, como também por suas dimensões espaciais e temporais que pouco contemplou a perspectiva temporal dos processos que ocorrem no geossistema, na paisagem e nas unidades taxonômicas desta (MAGALHÃES; SILVA; ZANELLA, 2010).

Uma das maiores críticas ao modelo de análise da paisagem Bertrand foi quanto à inserção do homem neste. Ao criar os termos "ação antrópica" e "exploração biológica" sem demais profundidade conceitual dentro do geossistema, Bertrand não só limitou o homem a um elemento exploratório da paisagem, como desconsiderou sua organização enquanto sociedade e agente modificador e modelador do espaço (BERNARDINO; OLIVEIRA; DINIZ, 2018).

Ao inserir as ações antrópicas e sociais no modelo geossistêmico, Bertrand passou a naturalizá-las, o que consequentemente fez com que, (MAGALHÃES; SILVA; ZANELLA, 2010, p. 15).

[...] os sistemas de poder, os interesses socioeconômicos, políticos, culturais e tantas outras manifestações sociais que regem as ações humanas na paisagem não são abordadas em sua gênese, dinâmica e evolução, ou seja, a 
análise geossistêmica não trata com a devida importância as manifestações sociais que geraram uma ação antrópica sobre a paisagem (MAGALHÃES; SILVA; ZANELLA, , 2010, p. 15).

Conforme destaca Guerra, Souza e Lustosa (2012), no contexto destas críticas e de que a Geografia estava sendo influenciada por outras correntes de pensamento, sobretudo, numa tendência entre Geografia Crítica e Geografia Cultural, Bertrand repensa suas proposições a respeito dos geossistemas e as reelabora em um sistema tripolar Geossistema-TerritórioPaisagem (Sistema GTP), que se baseia numa abordagem holística, diagonal e transversal, conforme a figura 03 .

Na nova proposição teórico-metodológica (FROLOVA, 2003, p. 1):

Claude e Georges Bertrand apontam que o sistema GTP não esgota toda a noção de paisagem, nem do meio geográfico. Seu objetivo é aproximar esses três conceitos ou noções para analisar como o ambiente geográfico trabalha em sua globalidade e compreender as interações entre eles. Segundo os autores, cada um desses subsistemas são objetos mais ou menos bem identificados e revelam os métodos já utilizados de forma eficaz (FROLOVA, 2003, p.1, tradução nossa).

De acordo com o sistema GTP de Claude e Georges Bertrand (2007), o ponto de partida para a compreensão do espaço geográfico em sua globalidade se daria em três diferentes categorias de análise que são que são a fonte "source" (geossistema), o recurso "ressource" (território) e a representação "ressourcement" (paisagem), as quais são regidas respectivamente por três tempos simultâneos distintos, "uma vez que o espaço se modifica e/ou se transfigura constantemente ao longo do tempo; enquanto que o tempo dos funcionamentos físico-químicos e biológicos é inversamente proporcional ao tempo do social e do econômico e ao tempo do simbólico" (GUERRA, SOUZA E LUSTOSA, 2012, P. 33). Conforme pode ser observado na figura 3 abaixo:

Figura 3: Proposta do Sistema GTP (Geossistema-Território-Paisagem).

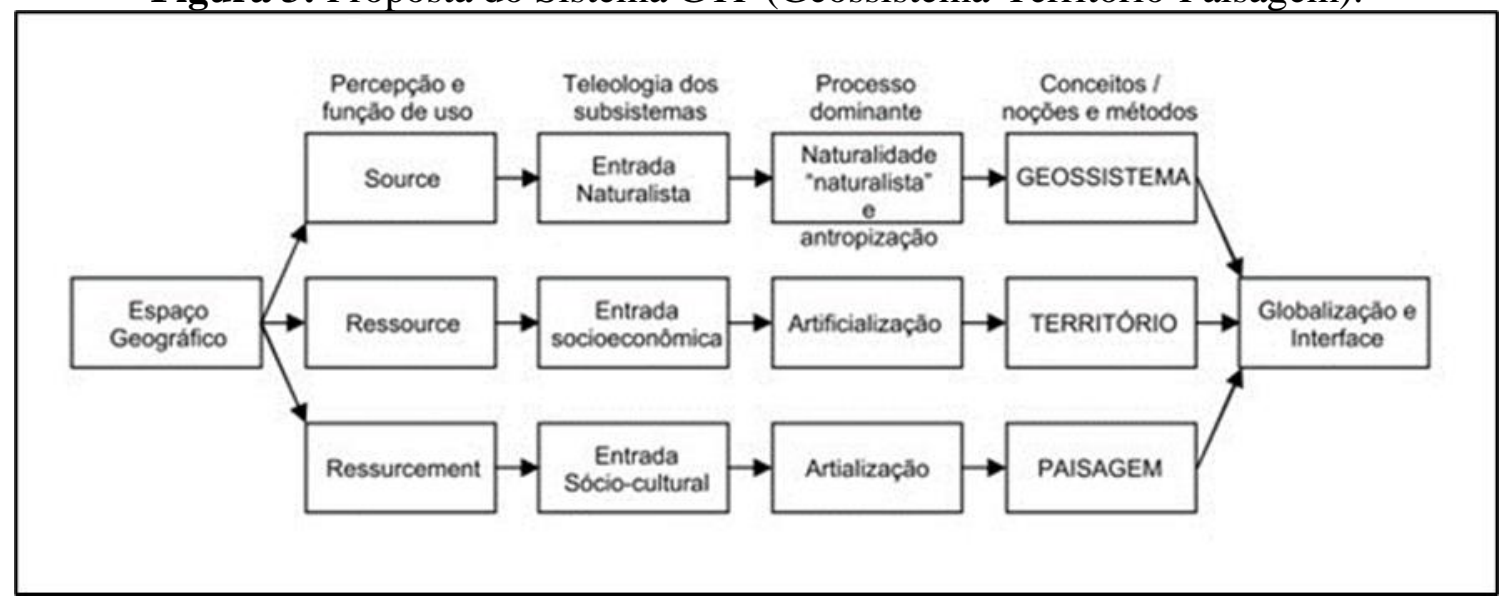

Fonte: Guerra, Souza e Lustosa (2012). 
Em caráter de compreensão, no Sistema GTP, o Geossistema é a fonte (source) totalmente natural, no qual a compreensão de espaço geográfico no tempo parte de seu funcionamento biofísico. O Território é o recurso (ressource), que trata das intervenções da sociedade (ação antrópica, mais especificamente) de acordo com seus objetivos e suas necessidades sobre o espaço considerado e a Paisagem (ressourcement) fornece as informações da sedimentação socioeconômica e cultural sobre o território.

Assim, acredita-se que a inserção dos conceitos de território e paisagem no modelo GTP não são redundantes (mas exprimem uma pesquisa de totalidade geográfica, pois representam a trajetória da pesquisa bertraniana de 1959 até 1991). Todavia, suprem a necessidade da dimensão humana e do simbólico participante na formação do ambiente, como aborda Neves (2017).

Diante disso, é importante salientar, que essa nova proposição teórico-metodológica de Bertrand através do sistema GTP (Geossistema-Território-Paisagem) emerge sob os avanços de sua proposta lançada em 1968 e que sem abortar antigas sistematizações relativas aos Geossistemas, procura através de seu amadurecimento científico ainda fornecer análises integradas nos estudos da paisagem em Geografia (GUERRA, SOUZA E LUSTOSA, 2012).

Com bem destaca Bernardino; Oliveira e Diniz (2018) "é nítida guinada das concepções e dos trabalhos de Georges Bertrand ao método fenomenológico, em detrimento do, até então utilizado, método indutivo", fato este explicado pela aproximação do autor ao universo teórico-metodológico da Geografia Humanista e Cultural que se instaurava na época. É perceptível que a abordagem GTP passa a evidenciar o pertencimento ao lugar, os aspectos culturais, as relações de poder e os modos como estes elementos estão sendo representados através da paisagem.

Almeja-se, assim, que o GTP seja um fio condutor de conteúdos geográficos, pois ele é de fato um modelo transdisciplinar assim como realizado com o geossistema de 1968 - em campo que pode ser um modelo operacional, a fim de se tornar uma grande ferramenta didática no estudo da sociedade - natureza que (BERTRAND, 2010).

\section{CARTOGRAFIA DAS PAISAGENS: REPRESENTAÇÕES INTEGRADORAS}

A Cartografia de Paisagens, denominada também Mapeamento de Geossistemas, ou Cartografia Geoambiental, é uma atividade de caráter físico-geográfico, e está preocupada com a representação de complexos naturais, também chamados de geossistemas, que compreendem áreas naturais resultantes da interação entre os componentes da natureza, influenciados em maior ou menor grau pela sociedade (CAVALCANTI, 2014, p.5). 
Para Bertrand, a cartografia das paisagens exige um inventário geográfico complexo e detalhado, onde seus levantamentos essenciais estão contidos em aspectos pedológicos, geomorfológicos, fitogeográficos, observações das águas superficiais e meteorológicas. Assim, em 1971, baseado em uma preocupação advinda desde o início dos estudos dos geossistemas, Bertrand definiu, formas e padrões funcionais baseado na escala e na homogeneidade de elementos, um sistema taxonômico com unidades superiores - zonas, domínios, regiões naturais - e unidades inferiores - geossistemas, geofácies, geótopo - onde o termo geossistema aparece como uma categoria, e onde ambas categorias são propostas em função da escala tempo-espacial.

A partir dos estudos iniciados por Bertrand, é possível observar que autores sucessores vêm desenvolvendo fundamentos teórico metodológicos para a representação da paisagem, com a finalidade de ter um produto que consiga integrar o ambiente em sua totalidade. Bólos (1981) afirma que a necessidade de estabelecer a dimensão da área a ser investigada levou à definição de sistemas de classificação em unidades, que representam o dimensionamento ou atribuição escalares ao conceito de paisagem.

A Cartografia de Paisagens, denominada também Mapeamento de Geossistemas, ou Cartografia Geoambiental, é uma atividade de caráter físico-geográfico, e está preocupada com a representação de complexos naturais, também chamados de geossistemas, que compreendem áreas naturais resultantes da interação entre os componentes da natureza, influenciados em maior ou menor grau pela sociedade (CAVALCANTI, 2014, p.5).

Venturi (1997) vai chamar atenção a respeito de que as unidades de paisagem apresentam vantagens, por apresentar e possibilitarem um dimensionamento mais definido e uma representação cartográfica precisa, entretanto, para pesquisas sobre as unidades de paisagem, não deve haver um modelo a ser seguido, uma vez que, esta metodologia dispõe de inúmeras possibilidades de pesquisa com vários dimensionamentos a serem trabalhados.

Por esta viabilidade, é possível que sejam realizados trabalhos como os de Rodriguez, Silva e Cavalcanti (2007), na obra intitulada "Geoecologia de Paisagens". Diante do contexto da obra, os autores dividem as unidades de paisagem de acordo com as escalas espaçotemporais, através de níveis espaciais da superfície, sendo eles: a regionalização geoecológica da paisagem e as unidades locais da paisagem. Através destes procedimentos, é possível verificar as tipologias da paisagem (classes, tipos, grupos e espécies), determinando sua funcionalidade e estrutura. Fazendo a relação com o modelo proposto por Bertrand, essas tipologias abordam claramente os diversos elementos integrados da paisagem: fatores e variáveis climáticas, geológicas, geomorfológicas, pedológicas, hídricas, bióticas e antrópicas. 
Rodriguez, Silva e Cavalcanti (2007, p.89) citam a cartografia das paisagens como o objeto final, consistindo na aplicação dos métodos de distinção e elaboração dos diferentes tipos de mapas de paisagem, através de diversas etapas, iniciando nos trabalhos de campo e seguindo o percurso até a obtenção do produto. Diante do exposto, fica claro que não se faz possível a representação da paisagem sem interpretar o todo com uma sensibilidade baseada na identificação dos principais contrastes paisagísticos observáveis.

Abordando uma perspectiva contemporânea, temos no desenvolvimento da ciência geográfica e na representação da paisagem, a inserção das ferramentas do Sensoriamento Remoto e Geoprocessamento, nos quais permitem a integração, análise e representação das paisagens por meio da manipulação e tratamento dos dados em ferramenta de Sistemas de Informações Geográficas (SIG).

\section{CONSIDERAÇÕES FINAIS}

Com caráter fundamental, o conceito de paisagem é primordial para o desenvolvimento da Ciência Geográfica. Assim, compreendê-la, analisar sua dinâmica, e realizar reflexões acerca de suas abrangências, se constitui como um exercício indispensável para se realizar pesquisas em Geografia, por isso, nesse artigo procurou enxergá-la sob um viés integrador.

A partir das abordagens e aplicações do conceito de Paisagem, foi possível a compreensão de que suas análises foram se desenvolvendo até chegarem a um ponto em que fosse possível realizar a expansão e utilização do conceito de forma multidisciplinar em diversas áreas do conhecimento. Por se tratar de abordagens teórico-metodológicas, suas reflexões não ficaram pautadas apenas para seus estudos, e sim, fundamentaram outras teorias igualmente fundamentais para a explicação dos fenômenos.

De certo, a introdução do pensamento de Bertrand na Geografia enfrentou críticas, contracorrentes e questionamentos, entretanto, o autor continuou em busca das adaptações necessárias para o aprimoramento dos estudos da paisagem. Desta maneira, a paisagem para Bertrand é considerada um conjunto único, indissociável e em perpetua evolução.

Ao demonstrar a aplicação do legado deixado pelo autor, nos leva a encarar quão complexo é a representação da paisagem, uma vez que, a partir de sua observação, somos levados a encarar não apenas o fenômeno que esta posto, mas sim, o conjunto de interações e ações que o mesmo recebe e atua em relação ao meio no qual se insere. 
Todas as abordagens aqui elencadas, tem a finalidade de que este estudo possa reafirmar a importância dos estudos da paisagem para a Ciência Geográfica e engrandecer, um pouco que seja os estudos relacionados sobre análise integrada como a deixada por Georges Bertrand.

\section{AGRADECIMENTOS}

A Coordenação de Aperfeiçoamento de Pessoal de Nível Superior (CAPES) pela concessão das bolsas de mestrado.

\section{REFERÊNCIAS}

AUGUSTO, Rafael Cardão. A Cartografia de paisagens e a perspectiva geossistêmica como subsídios ao planejamento ambiental. Revista Tamoios, São Gonçalo, v. 12, n. 1, p.144-153, jun. 2016.

BERTALANFFY, Ludwig von. Teoria Geral dos Sistemas. Tradução de Francisco M. Guimarães. Petrópolis: Vozes, 1973.

BERTRAND, Georges. Uma Geografia transversal e de travessias: o meio ambiente através dos territórios e das temporalidades. Tradutor: Messias Modesto dos Passos. Maringá: Massoni, 2007.

BERTRAND, Georges. Paysage et géographie physique globale. Esquisse méthodologique. Revue Géographique Des Pyrénées Et Du Sud-ouest, Toulouse, v. 39, n. 3, p.249-272, 1968.

BERTRAND, Georges. Paisagem e geografia física global: esboço metodológico. Cadernos de Ciências da Terra, São Paulo, v. 13, p. 1-27, 1972.

BERTRAND, Georges. Itinerario en torno al paisaje: uma epistemología de terreno para tiempos de crisis. Ería, v.81, p.5-38, 2010.

BOLÓS, M. I. C. Problemática actual de los estudios de paisaje integrado. Revista de geografía, v. 15, n. 1, p. 45-68, 1981.

BOLÓS, M. I. C. Essai d'analyse écologique de l'espace montagnard. L'Espace Géographique, Paris, v. 2, n. 3, p. 165-170, 1973.

CAVAlCANTI, Lucas Costa Souza. Cartografia de Paisagens: Fundamentos. São Paulo: Oficina de Textos, 2014.

CAVALCANTI, Lucas Costa Souza; CORRÊA, Antonio Carlos B. Da descrição de áreas às sínteses naturalistas: uma abordagem historiográfica sobre a ideia de 'áreas naturais'. Espaço \& Geografia, v.17, n. 2, p. 377- 422, 2014.

CHRISTOFOLETTI, Antonio. Modelagem de sistemas ambientais. São Paulo: Blucher, 1999. p. 1-18. 
FIGUEIREDO, Nice. Da importância dos artigos de revisão da literatura. Revista Brasileira de Biblioteconomia e Documentação. v. 23, p. 131-135, 1990.

FROLOVA, Marina. Bertrand, Claude e Georges. Une géographie traversière: L'environnement à travers territoires et temporalités. Biblio 3W, Revista Bibliográfica de Geografia e Ciências Sociais, Universidade de Barcelona, Vol. VIII, $n^{\circ} 432,5$ de março de 2003. Disponível em: <http://www.ub.es/geocrit/b3w-432.htm>. Acesso em: 24 maio 2019.

GREGORY, K. J. A natureza da Geografia Física. Rio de Janeiro, Bertrand Brasil. 1992.

GUERRA, Antônio José Teixeira.; MARÇAL, Mônica Santos. Geomorfologia Ambiental. Rio de Janeiro: Bertrand Brasil, 2006. 192 p.

GUERRA, Maria Daniely Freire; SOUZA, Marcos José Nogueira de; LUSTOSA, Jacqueline Pires Gonçalves. Revisitando a teroria geossistêmica de Bertrand no século XXI: aportes para o GTP (?). Geografia em Questão, [s.i], v. 5, n. 2, p.28-42, 2012. Semestral.

LIMBERGER, Leila. ABORDAGEM SISTÊMICA E COMPLEXIDADE NA GEOGRAFIA. Revista Geografia, Londrina, v. 15, n. 2, p.95-109, dez. 2006.

MAGALHÃES, Gledson Bezerra; SILVA, Edson Vicente da; ZANELLA, Maria Elisa. Análise geossistêmica: caminho para um entendimento holístico. Geopuc, Rio de Janeiro, v. 3, n. 5, p.1-17, 29 nov. 2010. Disponível em: <geopuc.geo.puc-/Artigo1ano3n1.pdf>. Acesso em: 24 maio 2019.

MEDEIROS, Diogo Bernardino Santos de; OLIVEIRA, Alisson Medeiros de; DINIZ, Marco Túlio Mendonça. Georges Bertrand e a Análise Integrada da Paisagem em Geografia. Revista de Geociências do Nordeste, Caicó, v. 4, n. 2, p.63-80, 2018.

MONTEIRO, Carlos Augusto Figueiredo. Geossistemas: a história de uma procura. São Paulo: Contexto, 2000.

MORAES, Antonio Carlos Robert. Geografia: Pequena História Crítica. São Paulo. Hucitec, 1994.

NEVES, Carlos Eduardo. A Geografia desconhecida de Georges Bertrand: Contribuições à discussão e aplicação do "Geossistema Complexo no Brasil". Revista de Estudos Geográficos - XIII Seminário da Pós-Graduação em Geografia, Rio Claro, 15(0): 139-166, jan./jun. 2017.

RODRIGUEZ, Jose Manuel Mateo; SILVA, Edson Vicente; CAVALCANTI, Agostinho Paula Brito. Geoecologia das paisagens: uma visão geossistêmica da análise ambiental. 2 ed. Fortaleza. Edições UFC. 2007. 222p.

SILVA, Márcio Luiz da. Paisagem e Geossistema: contexto histórico e abordagem teóricometodológica. Geoambiente On-line, Jataí, v. 11, p.163-185, 2008. Semestral.

SOCHAVA, Viktor Borisovich. O estudo do geossistema. Métodos em questão, n.16, p.01$51,1977$.

TRICART, Jean. Ecodinâmica. Rio de Janeiro, FIBGE-SUPREN, 1977. 
TROPPMAIR, Helmut; GALINA, Marcia Helena. GEOSSISTEMAS (Geosystems). Mercator, Fortaleza, v. 5, n. 10, p. p. 79 a 90, nov. 2008.

VENTURI, Luiz Antonio Bittar. Unidades de Paisagem como recurso metodológico aplicado na geografia física. In: VII Simpósio Brasileiro de Geografia Física Aplicada,7, Curitiba, Brasil.

VICENTE, Luiz Eduardo; PEREZ FILHO, Archimedez. Abordagem Sistêmica Geografia. Rio Claro: v. 28, n. 3, p. 345-362, set./dez., 2003.

Artigo recebido em: 28 de agosto de 2020. Artigo aceito em: 16 de novembro de 2020. Artigo publicado em: 05 de janeiro de 2021. 